\title{
ESTUDO DE IMPACTO AMBIENTAL (EIA) APLICADO À AMPLIAÇÃO DA UNIVERSIDADE FEDERAL DE SANTA MARIA - CAMPUS FREDERICO WESTPHALEN/RS
}

\author{
Fabiane Toniazzo', Laís Lavnitcki², Marcia Ludwig Henika3 ${ }^{3}$ Kelli Andreiza \\ Galvan ${ }^{4}$ e Aline Ferrão Custódio Pasini ${ }^{5}$
}

\begin{abstract}
Resumo: Atualmente, as questões relativas ao ambiente natural têm preocupado a sociedade, tomando proporções universais. Por este motivo, normas e legislações vêm se tornando, cada vez mais, importantes e efetivas. Logo, licenciamentos e estudos de impactos ambientais estão sendo utilizados como ferramentas, tendo-se como objetivo a minimização de impactos socioambientais. Este trabalho objetivou prever possíveis impactos que possam ser causados durante uma possível ampliação da Universidade Federal de Santa Maria (UFSM), campus Frederico Westphalen/RS. O desenvolvimento do estudo abrangeu visitas a campo, pesquisas bibliográficas e análise de documentos e materiais disponibilizados pela instituição. Com isso, utilizou-se a matriz de Leopold para "quantificar" os graus de impacto de cada atividade relacionada, avaliando se três possíveis formas de expansão territorial do campus. Tendo sido verificado que a segunda alternativa respeita os limites territoriais e explora de forma menos negativa os recursos naturais. Foi possível observar que através do EIA se analisou e levantou os impactos positivos e negativos mais importantes decorrentes desta ampliação, visando à construção de obras de infraestrutura e por meio destas informações foi possível indicar as medidas necessárias para a mitigação dos principais impactos negativos levantados.
\end{abstract}

Palavras-chave: Expansão universitária. Impacto socioambiental. Exploração ambiental.

\section{Introdução}

Hodiernamente, mais do que nunca, as questões relativas ao ambiente natural têm preocupado a sociedade, tomando proporções universais. Diante disso, de acordo com legislação e normas específicas como a Política Nacional de Meio Ambiente (BRASIL, 1981), Constituição Federal do Brasil (BRASIL, 1988) e resoluções do Conama $n^{\circ} 001$ (BRASIL, 1986) e $n^{\circ} 237$ (BRASIL, 1997), os empreendimentos e atividades que possuem um potencial de geração de impactos ambientais significativos devem elaborar o Estudo de Impacto Ambiental e respectivo Relatório de Impacto Ambiental (EIA/RIMA) como uma etapa do licenciamento, elaborada de acordo com o órgão ambiental que irá avaliar sua viabilidade e pedido de Licença Prévia (LP). Este procedimento tem como objetivo a minimização de impactos socioambientais, desde as etapas iniciais de seu planejamento e instalação, até a efetiva operação. De acordo com Pereira e Góes (2016) o principal objetivo é a prevenção do dano ambiental, devendo contemplar os impactos ambientais, a proposição de medidas mitigadoras e os planos de controle e monitoramento dos impactos identificados.

O EIA deve ser realizado por uma equipe multidisciplinar de especialistas que realizam um diagnóstico detalhado do ambiente e, a partir das características da construção e operação do empreendimento, deve-se identificar todas as alterações possíveis que resultarão dessas atividades, propondo as medidas mitigadoras. Já o Rima, segundo Oliveira e Bursztyn (2001), também se constitui em documento do processo de AIA (Avaliação de Impacto Ambiental), que deve esclarecer numa linguagem simples e corrente todos os elementos da proposta e do estudo para serem utilizados no processo de tomada de decisão e divulgados para o público em geral, inclusive proporcionando o

\footnotetext{
${ }^{1}$ E-mail: engtoniazzo@gmail.com

²E-mail: laisbruski_13@hotmail.com

33E-mail: marcia_henika@hotmail.com

${ }^{4}$ E-mail: kelliandreiza@gmail.com

5*E-mail: aline.passini@ufsm.br

${ }^{*}$ R. Sete de Setembro, s/n, Frederico Westphalen - RS, 98400-00
} 


\section{REA - Revista de estudos ambientais (Online) v.20, n. 2, p.6-20, jul./dez. 2018}

entendimento para as pessoas leigas no assunto. Esse relatório deve apresentar as conclusões do EIA e conter a discussão dos impactos positivos e negativos considerados relevantes. Afinal, busca-se quebrar barreiras culturais, visto que 0 desenvolvimento sustentável envolve não somente o uso de ações de menor impacto ambiental, mas também a quebra de paradigmas (SKRZEK; POSSAN, 2012).

Assim, este trabalho teve como objetivo principal, prever os impactos que possam ser causados no ambiente, resultantes da ampliação da Universidade Federal de Santa Maria (UFSM) Campus Frederico Westphalen, considerando as fases de planejamento, implantação, operação e desmobilização, quando for o caso, e os aspectos físicos, biológicos e socioeconômicos. Como objetivos específicos, procurou-se avaliar a viabilidade ambiental e propor, caso seja aceitável o nível de alteração do meio, além das medidas que deverão ser adotadas para reduzir os impactos negativos previstos - chamadas medidas mitigadoras -, maximizar os benefícios ambientais e, no caso de se observarem impactos irreversíveis, propor medidas compensatórias às eventuais perdas.

\section{Metodologia}

O desenvolvimento do estudo de impacto ambiental foi realizado nos meses de agosto a outubro do ano de 2016 e por se tratar da expansão de um empreendimento já existente foram realizadas visitas a campo para conhecimento e análise da área, assim como das atividades desenvolvidas. Após a identificação e avaliação das condições atuais, foram verificados os possíveis locais de expansão buscando comparar a situação atual e futura.

O conteúdo e desenvolvimento deste EIA estão de acordo com a legislação brasileira pertinente, obedecendo às normas da Constituição Federal de 1988, artigo 225, $\S 1^{\circ}$, inciso IV, que determina a realização de EIA/RIMA para empreendimentos que possam causar significativos impactos ambientais. Em complementação ao dispositivo constitucional, também foram observadas normas infraconstitucionais, como resoluções CONAMA no 01/86 e no 237/97. Para o desenvolvimento do EIA foram realizadas pesquisas bibliográficas em periódicos, legislações, assim como, em diferentes instituições de pesquisa que detém conhecimento sobre a região, para que fossem levantados dados pretéritos existentes. Através das visitas a campo, foram levantados dados de campo para o conhecimento dos aspectos físicos (ar, água, solo, clima), bióticos (flora e fauna) e antrópicos (socioeconomia da região) da região onde se pretende ampliar 0 empreendimento através de plantas, imagens, informações e arquivos de caracterização disponibilizados pela UFSM Campus Frederico Westphalen-RS.

\section{1 Área de estudo}

A área de estudo é a unidade de ensino ligada a UFSM, com extensão no município de Frederico Westphalen, Noroeste do estado do Rio Grande do Sul (Figura 1), localizada no endereço: Linha Sete de Setembro s/n, BR 386, km 40, distado a 8,4 $\mathrm{km}$ do centro da cidade.

O empreendimento estudado iniciou suas atividades no mês de julho do ano de 2007, tendo como princípio levar o meio técnico-científico da UFSM também ao norte do estado do Rio Grande do Sul, proporcionando aos jovens da região novas oportunidades. A instituição conta com mais de 900 alunos e atualmente oferece seis cursos de graduação sendo Agronomia, Engenharia ambiental e sanitária, Engenharia florestal, Jornalismo, Relações públicas e Sistemas de Informação. Além disso, oferece um curso de mestrado em Agronomia agricultura e ambiente e um curso a distância em Licenciatura de computação.

Em constante desenvolvimento, a instituição da UFSM do campus de Frederico Westphalen compreende uma área de 104 hectares e prevê a abertura de novos cursos, sendo necessário realizar a ampliação do campus com a construção de novos prédios para suprir a necessidade atual que já se faz presente devido à falta de salas de aula, assim como suprir as demandas futuras.

\subsubsection{Diagnóstico Ambiental}

Para melhor conhecimento das características ambientais da área de estudo foi realizado um diagnóstico ambiental do meio físico, biótico e social. 


\section{REA - Revista de estudos ambientais (Online) v.20, n. 2, p.6-20, jul./dez. 2018}

Figura 1 - Localização da UFSM campus Frederico Westphalen/RS

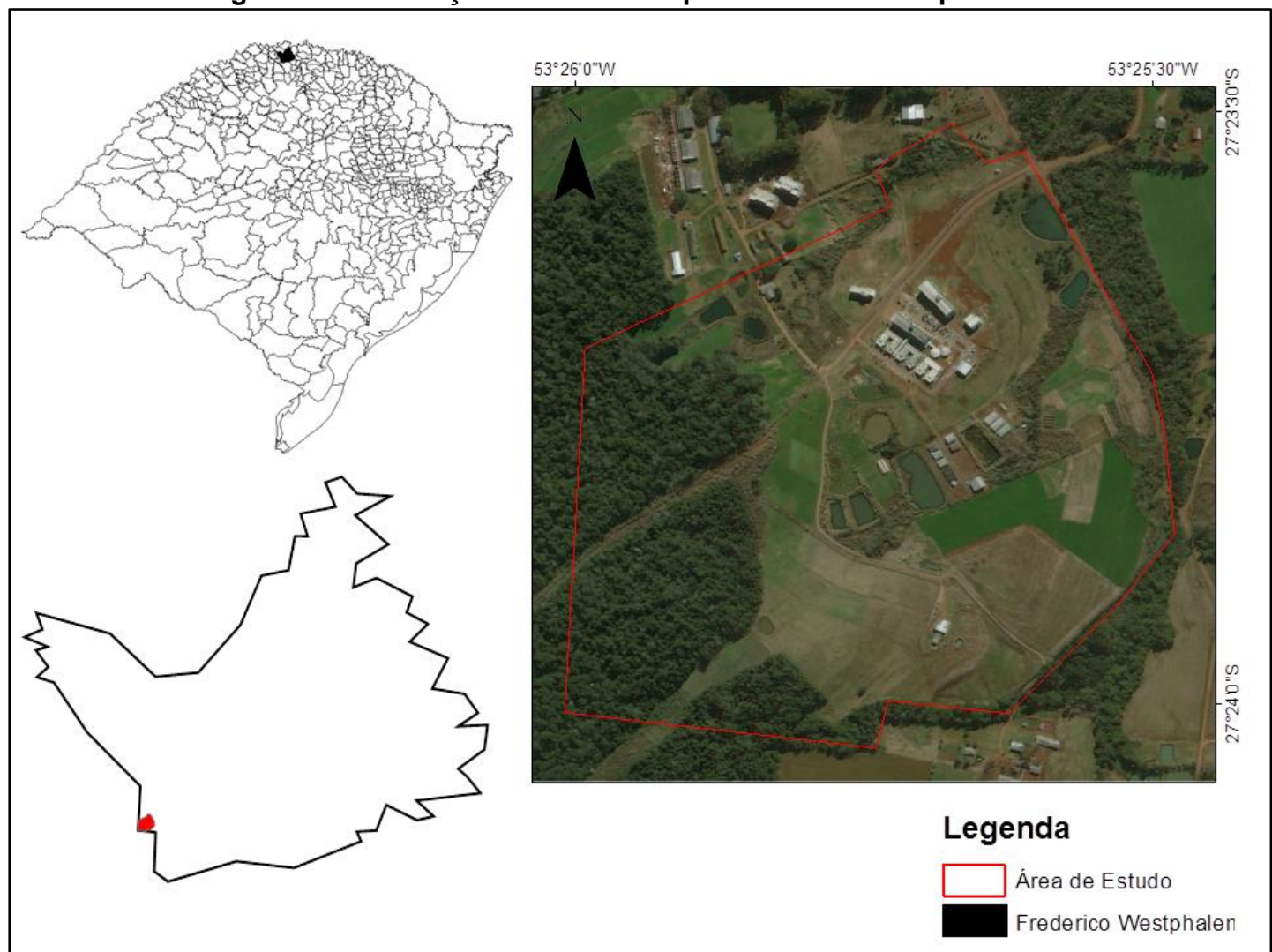

Fonte: Adaptado de Google Earth (2018)

\section{a) Meio físico}

A geologia e geomorfologia de Frederico Westphalen estão inseridas na Formação Serra Geral, sendo constituída por rochas efusivas básicas continentais, comumente basaltos ou fenobasaltos, com diques e corpos tabulares diabásicos, eventualmente intercalados por rochas areníticas eólicas da Formação Botucatu, além de rochas sedimentares, em menores proporções, correspondentes à Formação Tupanciretã (EMBRAPA, 2011). Ainda segundo o mesmo autor a caraterização do embasamento geológico regional tem sido, de certa forma, aceita de maneira muito generalizada como um domínio de basaltos, com distribuição de relevo distinta. De forma geral, tem-se a formação de chapadas remodeladas e serras, restos aplainados $e$ espigões rochosos em direção ao Uruguai. A área de estudo apresenta o relevo ondulado, com cotas de altitude entre 435 metros na parte mais baixa do terreno, e 526 metros no ponto mais elevado, próximo ao limite sudoeste. $\mathrm{Na}$ extremidade nordeste da área de estudo, o terreno apresenta uma declividade mais acentuada até próximo às margens do rio Pardo (EMBRAPA, 2011).

O solo da área de estudo é classificado como latossolo vermelho distrófico característico de relevos ondulados, cores avermelhadas devido aos altos teores e à natureza dos óxidos de ferro, além de serem profundos e porosos, podendo apresentar baixa fertilidade (EMBRAPA, 2011; ORTIGARA et al., 2014).

Quanto a hidrografia, o município de Frederico Westphalen faz parte da bacia hidrográfica do rio da Várzea. De acordo com - Plano Municipal de Saneamento Básico de Frederico Westphalen (PREFEITURA MUNICIPAL DE FREDERICO WESTPHALEN, 2011), a bacia do rio da Várzea é contribuinte da bacia do rio Uruguai, integrante da bacia do rio da Prata, cujas águas deságuam no Oceano Attântico. Os principais cursos d'água formadores da bacia hidrográfica do rio da Várzea é o próprio rio da Várzea e Guarita

$\mathrm{Na}$ área de estudo, encontra-se um grande número de represas d'água (açudes), nascentes e córregos de água, sendo dois destes utilizados como limites naturais do imóvel (Figura 2). O rio localizado no limite sul 


\section{REA - Revista de estudos ambientais (Online) v.20, n. 2, p.6-20, jul./dez. 2018}

da propriedade percorre um total de aproximadamente 953 metros e encontra-se em determinado ponto com o rio Pardo, que percorre aproximadamente 1.755 metros no limite leste/nordeste do Campus. Além destes, encontram-se na área seis nascentes, três córregos tributários dos rios principais e mais onze represas (açudes).

\section{Figura 2 - Localização dos rios, nascentes e açudes na área do empreendimento}

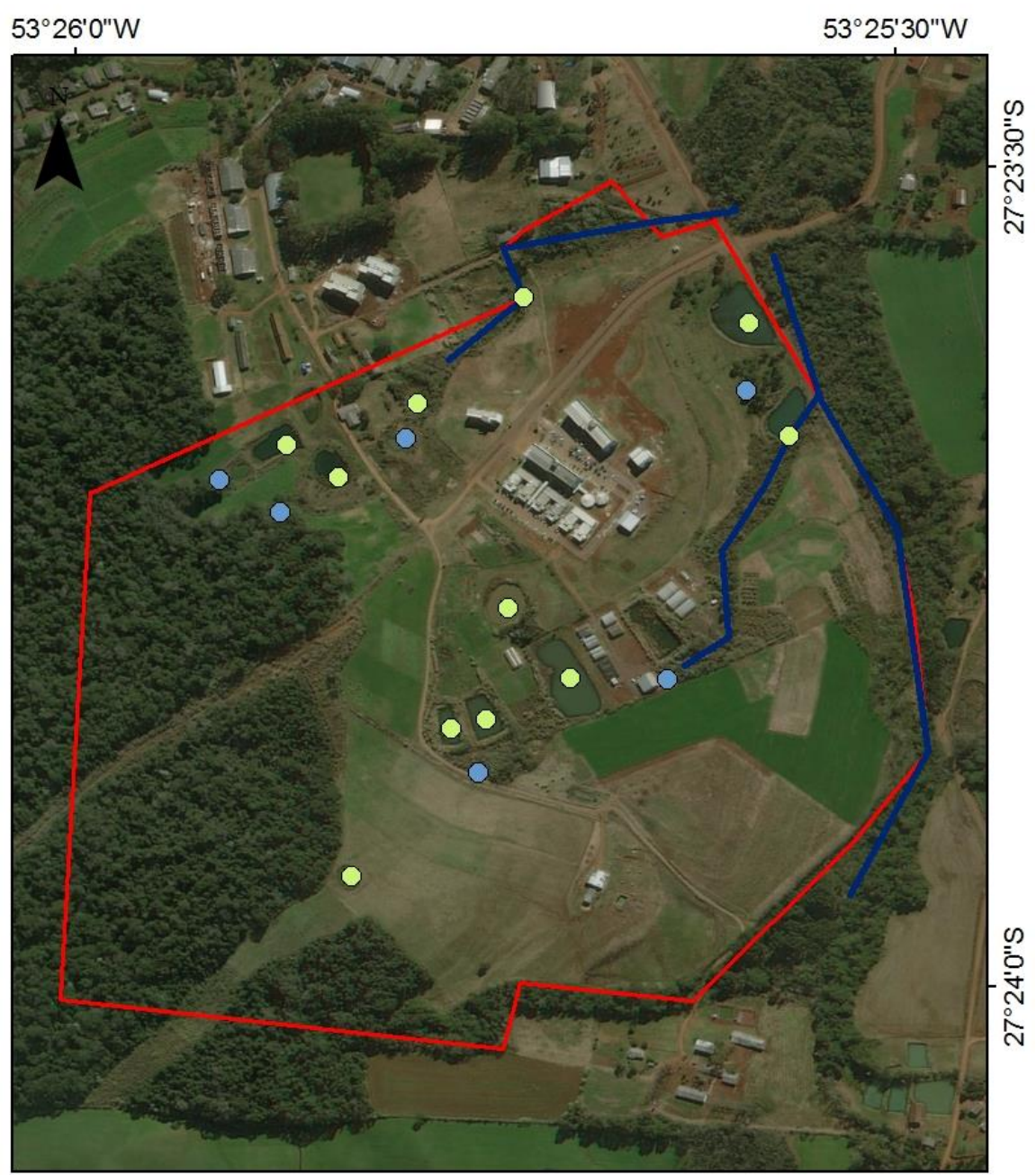

\section{Legenda}
Açudes
Nascente
Curso d'água Área de Estudo

Fonte: Adaptado de Google Earth (2018)

A região de Frederico Westphalen, de acordo com a classificação de Köppen apresenta um clima subtropical (Cfa - clima temperado húmido com verão quente), com chuvas bem distribuídas durante 0 ano e com temperatura média anual de $18^{\circ} \mathrm{C}$. Durante os meses mais quentes, a temperatura média é superior a $22^{\circ} \mathrm{C}$, com a média das máximas próxima a $31^{\circ} \mathrm{C}$. Durante o inverno, a média da temperatura é de $10^{\circ} \mathrm{C}$, com registro de temperaturas mínimas inferiores a $0^{\circ} \mathrm{C}$.

\section{b) Meio biótico}

Segundo o mapa de biomas do Brasil (IBGE, 2004) Frederico Westphalen está localizado no bioma Mata Atlântica, e quando analisada a florística da área de estudo, podese constatar que a ocupação do solo da área de estudo é dividida em diversos setores produtivos, contendo reflorestamento realizado abaixo dos prédios principais, onde se encontram também inúmeras araucárias, grande extensão de pastagem, como também 


\section{REA - Revista de estudos ambientais (Online) v.20, n. 2, p.6-20, jul./dez. 2018}

plantações realizadas pelos estudantes para experimentos, além da grande quantidade de mata ciliar e florestas nativas (Floresta Estacional Decidual).

De acordo com Maffra (2011) o local tem um fragmento de floresta Estacional Decidual com, aproximadamente 15 ha, outra de 33 ha e uma menor com 5 ha, todas a 566 $\mathrm{m}$ de altitude.

\section{c) Meio social}

Frederico Westphalen, de acordo com Instituto Brasileiro de Geografia e Estatística (IBGE, 2010), possui uma população estimada de 30.558 habitantes, com uma densidade demográfica de 108,85 $\mathrm{hab} / \mathrm{km}^{2}$. A densidade populacional está ligada principalmente a instalação de universidades no município, exemplo disso foi a construção da UFSM Campus FW em 2007, o que auxiliou no aumento no número de habitantes e na movimentação econômica do município (Tabela 1).

No campus são realizadas diversas atividades que fazem uso e ocupação do solo, tendo a predominância de experimentos com as mais diversas culturas realizadas pelos alunos durante suas pesquisas. $O$ uso do solo se dá também por infraestruturas, tendo-se atualmente três prédios em uso para as atividades acadêmicas, dois prédios destinados à casa do estudante e um em construção, devido à demanda de estrutura para pesquisa.

Tabela 1 - Evolução dos habitantes em Frederico Westphalen - RS

\begin{tabular}{cccc}
\hline Ano & Frederico Westphalen & Rio Grande do Sul & Brasil \\
\hline 1991 & 24.935 & 9.138 .670 & 146.825 .475 \\
1996 & 27.068 & 9.568 .523 & 156.032 .944 \\
2000 & 26.759 & 10.187 .798 & 169.799 .170 \\
2007 & 27.308 & 10.582 .840 & 183.987 .291 \\
2010 & $\mathbf{2 8 . 8 4 3}$ & $\mathbf{1 0 . 6 9 3 . 9 2 9}$ & $\mathbf{1 9 0 . 7 5 5 . 7 9 9}$ \\
\hline
\end{tabular}

Fonte: IBGE (2010)

Pelo fato de o empreendimento localizar-se na área rural do município com menor densidade demográfica, são poucos os residentes próximos a área de estudo. A ocupação existente é dada por propriedades particulares, lavouras, vegetação nativa e pensões que são ocupadas por estudantes da UFSM Campus Frederico Westphalen e Instituto Federal Farroupilha.

\subsection{Ferramenta utilizada para avaliação dos impactos ambientais}

A matriz de Leopold é um dos principais métodos de avaliação de impacto ambiental sendo baseada em uma lista de 100 ações com potencial de possíveis provedores de impacto ambiental e 88 características ambientais (FINUCCI, 2010). Faz-se necessário, inicialmente, assinalar todas as possíveis interações entre as ações e os fatores, para que posteriormente se estabeleça a magnitude e a importância de cada impacto em uma escala que varia de $1 \mathrm{a}$ 10. A partir disto, é possível identificar e avaliar se o impacto em questão é positivo ou negativo (OLIVEIRA; MOURA, 2009). Na verificação de impactos para a implantação e operação do empreendimento, foram determinados valores que expressam sua magnitude e significância em relação ao meio ambiente e à população demonstradas em duas matrizes, uma para a instalação do empreendimento e outra para a operação do empreendimento. Desta forma, a ponderação de valores foi escolhida conforme a Tabela 2 , tendo-se uma abrangência e magnitude dos impactos caracterizados entre negativos $e$ positivos, conforme a Tabela 3 .

Foram elaboradas também alternativas de ampliação e construção de novos prédios para que se pudessem avaliar as condições de acordo com cada área, sendo escolhida a alternativa que melhor se adequasse e causasse menor impacto, realizando-se assim, as matrizes citadas anteriormente de acordo com os impactos gerados em cada fase. A ampliação do empreendimento contará com a construção de novos prédios contendo salas de aulas, laboratórios e término de algumas construções, como é o caso da segunda casa do estudante. Além disso, vê-se a necessidade da construção do restaurante universitário e auditório. Tal fato é visto por parte dos envolvidos como mudança promissora à localidade. Entretanto, como 


\section{REA - Revista de estudos ambientais (Online) v.20, n. 2, p.6-20, jul./dez. 2018}

toda ação antrópica no meio ambiente gera impactos, sejam eles positivos ou negativos, os eixos econômico, social e ambiental irão sofrer mudanças, sendo que para a minimização dos impactos tem-se a necessidade de regularizar a situação da construção do campus de acordo com normas e legislações brasileiras.

Tabela 2- Ponderação de valores para a avaliação dos impactos ambientais

\begin{tabular}{cccccccc}
\hline $\begin{array}{c}\text { Ponderação } \\
\text { de valores }\end{array}$ & -10 & -5 & -1 & 0 & 1 & 5 & 10 \\
\hline $\begin{array}{c}\text { Magnitude de } \\
\text { Impacto }\end{array}$ & $\begin{array}{c}\text { Alto } \\
\text { Impacto } \\
\text { Negativo }\end{array}$ & $\begin{array}{c}\text { Médio } \\
\text { Impacto } \\
\text { Negativo }\end{array}$ & $\begin{array}{c}\text { Baixo } \\
\text { Impacto } \\
\text { Negativo }\end{array}$ & $\begin{array}{c}\text { Não } \\
\text { Existe } \\
\text { Impacto }\end{array}$ & $\begin{array}{c}\text { Baixo } \\
\text { Impacto } \\
\text { Positivo }\end{array}$ & $\begin{array}{c}\text { Médio } \\
\text { Impacto } \\
\text { Positivo }\end{array}$ & $\begin{array}{c}\text { Alto } \\
\text { Impacto } \\
\text { Positivo }\end{array}$ \\
\hline
\end{tabular}

Fonte: Adaptado de Sánchez (2013)

Tabela 3 - Abrangência e magnitude dos impactos

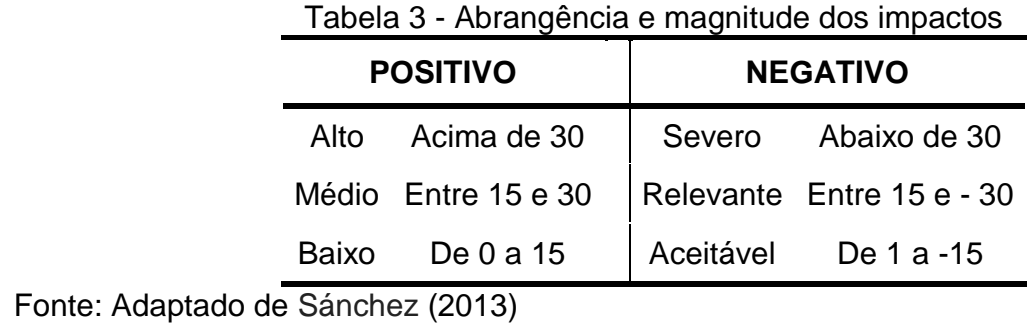

Para a ampliação da unidade de ensino foram levados em conta fatores como o fluxo de posicionamento dos prédios e construções já existentes, bem como os novos limites territoriais impostos devido ao desmembramento do Colégio Agrícola de Frederico Westphalen, pertencente a UFSM, atualmente federalizado como Instituto Federal Farroupilha. Assim, foram elaboradas três alternativas de ampliação e construção e avaliados os impactos durante as fases de implantação e operação.

\subsubsection{Alternativa número 1}

A alternativa de número 1 seria a ampliação do campus próximo a mata nativa (Figura 3), a qual teria os seguintes impactos:

a) Fase de Implantação

Impactos Negativos: Possivelmente será necessária supressão de boa parte da vegetação nativa, 0 que causaria descumprimento da lei, bem como agressivas alterações na biodiversidade local. Ainda é possível a ocorrência de alterações das características e qualidade da água, e solo, além da compactação deste último, causando assim problemas de erosão. E ainda a alteração da paisagem e geração de resíduos sólidos, causando alto impacto no meio ambiente.

Impactos Positivos: Elevação no movimento econômico local b) Fase de Operação

Impactos Negativos: Aumento do fluxo de transportes, gerando maior concentração de gases poluentes, aumento do nível de barulho. Continua modificação da paisagem local, bem como da qualidade ambiental.

Impactos Positivos: Melhor atendimento ao público, cessando necessidades atuais, e ainda agregação de valor nas áreas próximas e maior movimentação do comércio de bens $e$ serviços local.

\subsubsection{Alternativa número 2}

A segunda alternativa seria que a ampliação através de novas construções, seguisse 0 fluxo de construção já estabelecido por edificações anteriores (Figura 4).

a) Fase de Implantação

Impactos Negativos: Alterações das características e qualidade da água e solo, além da compactação deste último, causando assim problemas de erosão. $E$ ainda a alteração da paisagem e geração de resíduos sólidos.

Impactos Positivos: Elevação no movimento econômico local 
REA - Revista de estudos ambientais (Online) v.20, n. 2, p.6-20, jul./dez. 2018

Figura 3 - Alternativa um de ampliação para o empreendimento

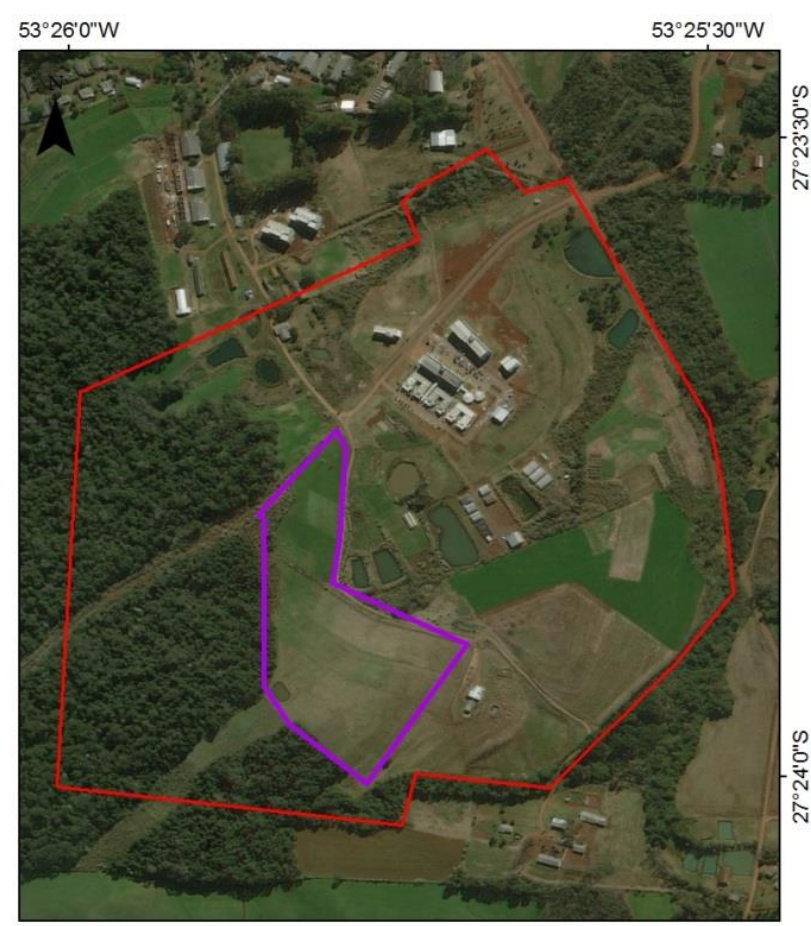

\section{Legenda}

$\square$ Alternativa $1 \square$ Área de Estudo

Fonte: Adaptado de Google Earth (2018)

Figura 4 - Alternativa dois para ampliação do empreendimento

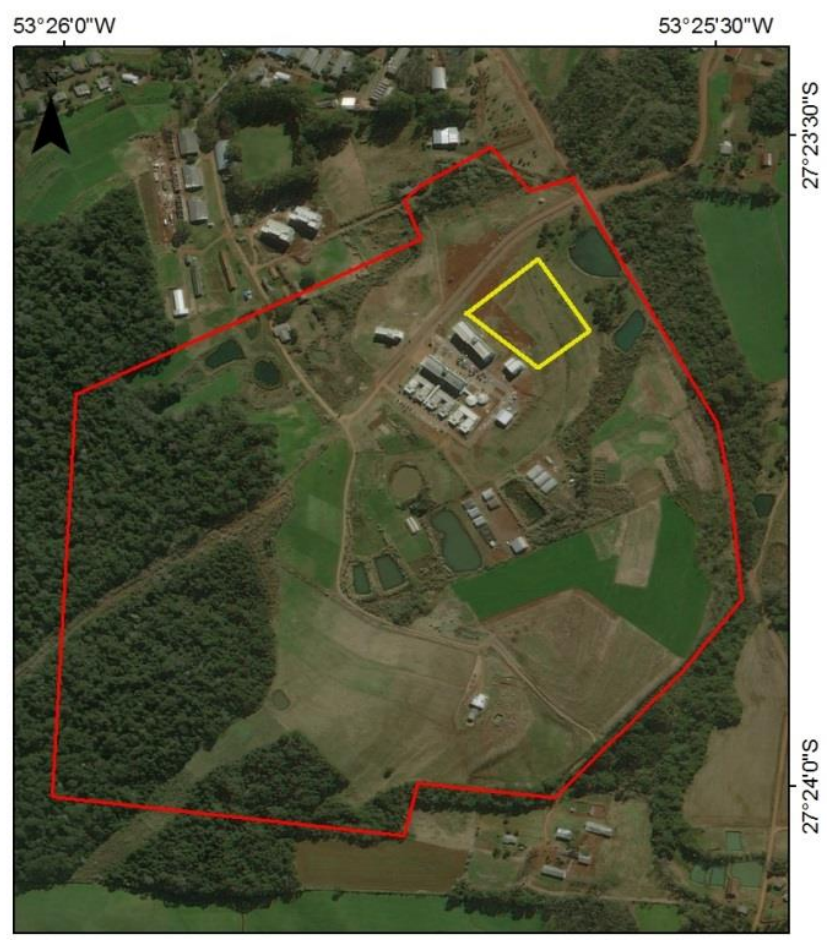

\section{Legenda}

Alternativa $2 \square$ Área de Estudo

Fonte: Adaptado de Google Earth (2018) 


\section{REA - Revista de estudos ambientais (Online) v.20, n. 2, p.6-20, jul./dez. 2018}

b) Fase de Operação

Impactos Negativos: Aumento do fluxo de transportes, gerando maior concentração de gases poluentes e aumento do nível de barulho, além de modificação da paisagem local e consequentemente da qualidade ambiental das áreas afetadas.

\subsubsection{Alternativa número 3}

E a terceira alternativa, que seria a não implantação do empreendimento, onde se tem os seguintes impactos gerados ambiente natural.

Impacto Positivo: Preservação do

Impacto Negativo: Degradação da área já explorada, provocando modificações no ambiente local, porém em menor proporção e intensidade que as demais alternativas. Como impacto negativo, tem-se também questões do desenvolvimento local e municipal com estagnação do crescimento da instituição, perda de oportunidades de ensino para a região e falta de profissionais.

\section{Resultados e discussão}

Avaliando-se as três alternativas, é possível verificar-se que a segunda alternativa respeita os limites territoriais, explora de forma menos negativa os recursos naturais.

Diante disso, a área que irá sofrer influência direta é o local onde irá ocorrer a construção, onde há presença de banhados, açudes, córregos de água próximos que podem ser afetados com a sua ampliação caso não sejam tomadas as providências e cuidados necessários. Há também a vegetação do meio, bem como a mata nativa utilizada para estudo e aulas práticas de

\author{
Impactos Positivos: Melhor \\ atendimento ao público, sanando \\ necessidades atuais, e ainda agregação de \\ valor nas áreas próximas e maior \\ movimentação do comércio de bens $e$ \\ serviços local.
}

alguns cursos, que devem ser preservados, além de se ter cuidado com o solo que é passível de contaminação.

Outro fator importante é o tráfego intensivo, principalmente nos dias de segunda à sexta-feira, de pessoas e veículos no local, sendo estes acadêmicos, visitantes, servidores, funcionários e professores da instituição. Deve-se ainda levar em conta de que a maioria destes utilizam de serviços que devem ser mantidos como energia elétrica, água, internet e afins, por serem necessários ao desenvolvimento das atividades acadêmicas e administrativas, sendo importante lembrar que a universidade conta com a Casa do Estudante, onde seus moradores dependem destes serviços em tempo integral.

Devido o local ser margeado por propriedades rurais particulares, as mesmas poderão ser afetadas indiretamente, devido ao aumento de movimentação de pessoas no local, mas tendo sua importância, devido a movimentação econômica da região, pelo uso de moradia, alimentação e lazer da mesma, contribuindo para seu desenvolvimento, evidência e expansão.

\subsection{Principais impactos envolvidos}

Observou-se os prováveis impactos positivos bem como os negativos, tanto no espaço abiótico, como biótico nas fases do projeto a ser implantado. Sendo que cada qual possui impactos de diferentes magnitudes (Quadro 1).

Quadro 1 - Identificação e avaliação dos impactos (Continua)

\begin{tabular}{|c|c|c|c|c|c|c|c|c|c|c|}
\hline & $\begin{array}{l}\text { Impacto } \\
\text { Ambiental }\end{array}$ & $\begin{array}{l}\text { Ocorrência do } \\
\text { Impacto }\end{array}$ & ID & II & IPR & IN & IP & IT & IL & ILP \\
\hline \multirow[b]{2}{*}{ SOLO } & $\begin{array}{l}\text { Alteração da } \\
\text { qualidade do solo }\end{array}$ & $\begin{array}{l}\text { Impermeabilização da } \\
\text { superfície do solo }\end{array}$ & $x$ & $x$ & $x$ & $x$ & & & $x$ & $x$ \\
\hline & Erosão pluvial & $\begin{array}{c}\text { Devido à } \\
\text { terraplanagem e } \\
\text { impermeabilização do } \\
\text { solo }\end{array}$ & $x$ & & & $x$ & & $x$ & $x$ & $x$ \\
\hline
\end{tabular}




\section{REA - Revista de estudos ambientais (Online) \\ v.20, n. 2, p.6-20, jul./dez. 2018}

Quadro 1 - Identificação e avaliação dos impactos (Conclusão)

\begin{tabular}{|c|c|c|c|c|c|c|c|c|c|c|}
\hline & $\begin{array}{l}\text { Impacto } \\
\text { Ambiental }\end{array}$ & $\begin{array}{l}\text { Ocorrência do } \\
\text { Impacto }\end{array}$ & ID & II & IPR & IN & IP & IT & IL & ILP \\
\hline $\begin{array}{c}\text { RECURSOS } \\
\text { HÍDRICOS }\end{array}$ & $\begin{array}{l}\text { Modificação da } \\
\text { qualidade das } \\
\text { águas }\end{array}$ & $\begin{array}{c}\text { Disposição } \\
\text { inadequada de } \\
\text { resíduos sólidos }\end{array}$ & $X$ & & $X$ & $x$ & & & & $x$ \\
\hline$A R$ & $\begin{array}{c}\text { Alteração da } \\
\text { qualidade do ar }\end{array}$ & $\begin{array}{c}\text { Aumento do fluxo de } \\
\text { transportes }\end{array}$ & & $X$ & $x$ & $x$ & $X$ & & $x$ & $x$ \\
\hline FLORA & $\begin{array}{c}\text { Alteração da } \\
\text { paisagem e } \\
\text { modificação da } \\
\text { permeabilidade }\end{array}$ & $\begin{array}{l}\text { Remoção da } \\
\text { vegetação }\end{array}$ & $x$ & $x$ & $x$ & $x$ & & & $x$ & $X$ \\
\hline SONORO & $\begin{array}{l}\text { Perturbação do } \\
\text { som para os } \\
\text { moradores } \\
\text { próximos }\end{array}$ & $\begin{array}{l}\text { Aumento do nível de } \\
\text { barulho provocado } \\
\text { pelo fluxo de } \\
\text { transporte }\end{array}$ & & $x$ & & $x$ & & & $x$ & \\
\hline
\end{tabular}

As matrizes de interação de impactos,

valores aos mesmos, conforme estabelecidos Tabelas 4 e 5, permitem a atribuição de nas Tabelas 2 e 3.

Tabela 4 - Matriz de impactos fase de implantação (Continua) MEIO FÍSICO

\begin{tabular}{|c|c|c|c|c|c|c|c|c|}
\hline MATRIZ & 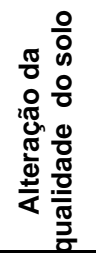 & 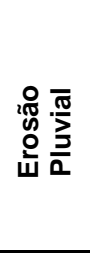 & 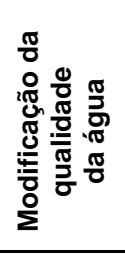 & 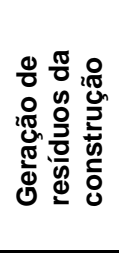 & 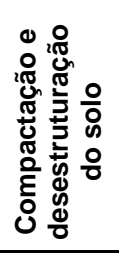 & 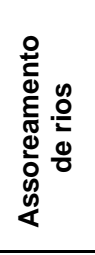 & 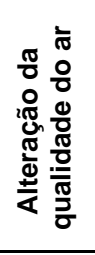 & 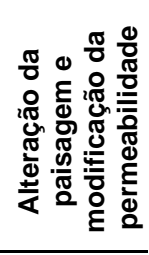 \\
\hline Impermeabilidade do solo & -10 & -10 & -5 & -1 & -10 & -5 & 0 & -10 \\
\hline Terraplanagem & -10 & -5 & -5 & -1 & -5 & -1 & -1 & -10 \\
\hline $\begin{array}{l}\text { Disposição inadequada de resíduos } \\
\text { sólidos }\end{array}$ & -10 & -5 & -10 & -10 & -1 & -5 & -5 & -5 \\
\hline $\begin{array}{l}\text { Aumento do fluxo de transportes } \\
\text { pesados }\end{array}$ & -10 & -10 & -1 & -1 & -5 & -5 & -5 & -10 \\
\hline Remoção da vegetação & -5 & -5 & -10 & -5 & -5 & -10 & -5 & -10 \\
\hline $\begin{array}{l}\text { Aumento do nível de barulho } \\
\text { provocado pelo fluxo de veículos }\end{array}$ & 0 & 0 & 0 & -1 & 0 & 0 & -1 & 0 \\
\hline Arrecadação de Impostos & 0 & 0 & 0 & 0 & 0 & 0 & 0 & 0 \\
\hline $\begin{array}{l}\text { Aumento de procura de } \\
\text { mão-de-obra }\end{array}$ & 0 & 0 & 0 & 0 & 0 & 0 & 0 & 0 \\
\hline $\begin{array}{l}\text { Aumento de vagas na } \\
\text { instituição de ensino }\end{array}$ & 0 & 0 & 0 & 0 & 0 & 0 & 0 & 0 \\
\hline Consumo de bens e serviços & 0 & 0 & 0 & 1 & 0 & 0 & 0 & 0 \\
\hline Geração de emprego & 0 & 0 & 0 & 5 & 0 & 0 & 0 & 0 \\
\hline $\begin{array}{c}\text { Aumento na procura por } \\
\text { empregos }\end{array}$ & 0 & 0 & 0 & 0 & 0 & 0 & 0 & 0 \\
\hline Total & -45 & -35 & -31 & -13 & -26 & -26 & -17 & -45 \\
\hline
\end{tabular}




\section{REA - Revista de estudos ambientais (Online) \\ v.20, n. 2, p.6-20, jul./dez. 2018}

Tabela 4 - Matriz de impactos fase de implantação (Conclusão)

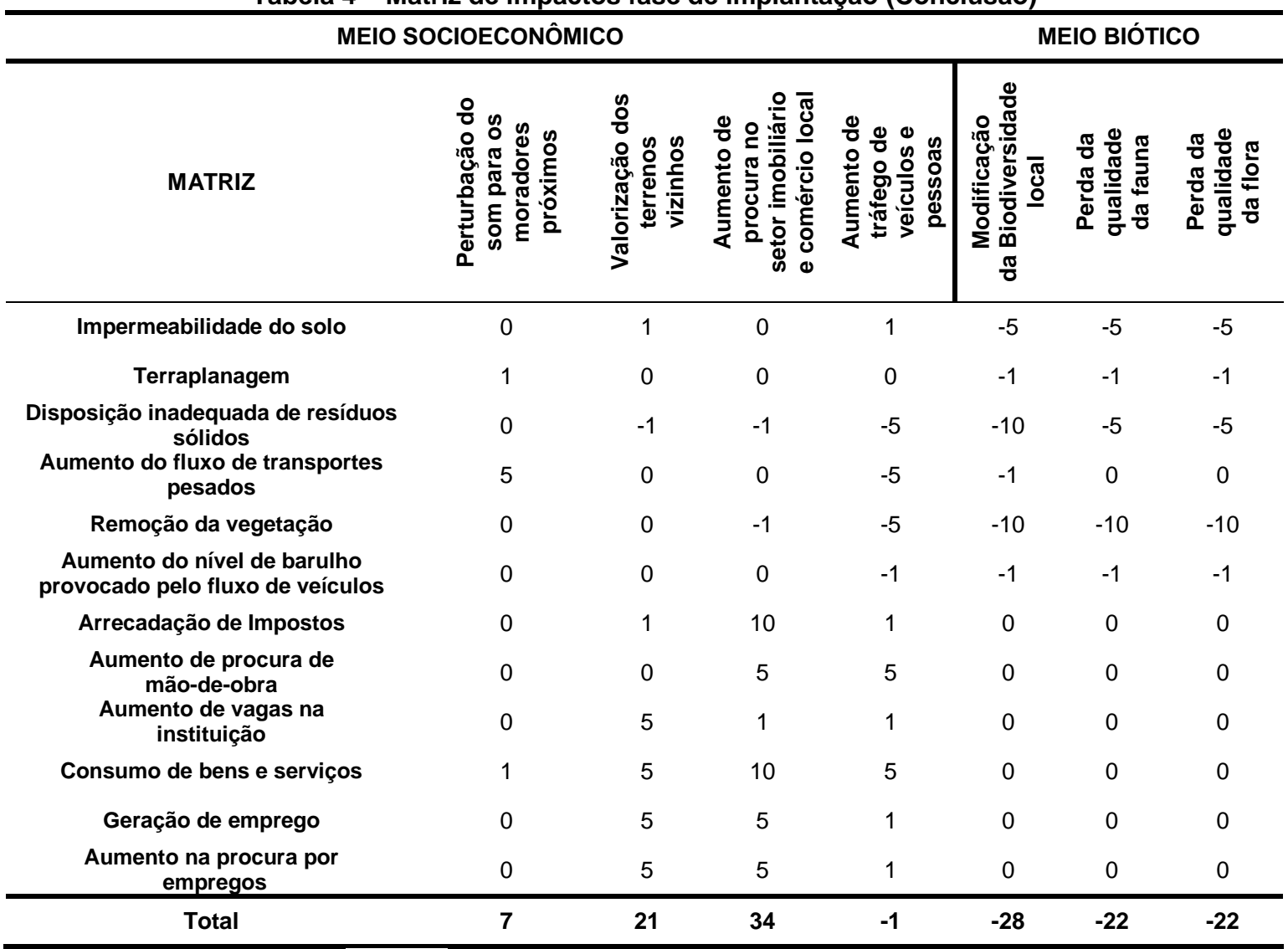

Fonte: Adaptado de Sánchez (2013)

Tabela 5 - Matriz de impactos fase de operação (Continua) MEIO FISICO

\begin{tabular}{|c|c|c|c|c|c|c|c|c|}
\hline MATRIZ & 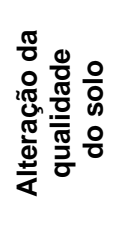 & 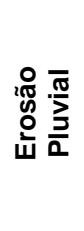 & 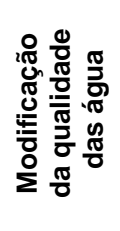 & 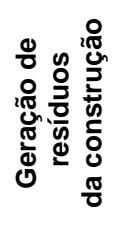 & 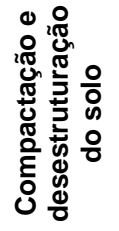 & 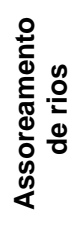 & 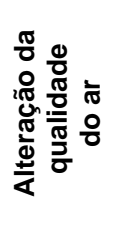 & 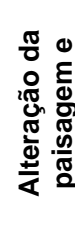 \\
\hline Impermeabilidade do solo & -5 & -10 & -10 & 0 & -10 & -5 & 0 & -5 \\
\hline Terraplanagem & 0 & 0 & 0 & 0 & 0 & 0 & 0 & 0 \\
\hline $\begin{array}{l}\text { Disposição inadequada de resíduos } \\
\text { sólidos }\end{array}$ & -5 & -5 & -10 & -10 & -5 & -10 & -10 & -5 \\
\hline $\begin{array}{l}\text { Aumento do fluxo de transportes } \\
\text { pesados }\end{array}$ & -1 & -1 & 0 & -1 & -5 & -1 & -10 & -5 \\
\hline Remoção da vegetação & -1 & -5 & -10 & -5 & -5 & -10 & -10 & -10 \\
\hline $\begin{array}{l}\text { Aumento do nível de barulho } \\
\text { provocado pelo fluxo de veículos }\end{array}$ & 0 & 0 & 0 & 0 & 0 & 0 & 0 & 0 \\
\hline Arrecadação de Impostos & 0 & 0 & 0 & 0 & 0 & 0 & 0 & 0 \\
\hline $\begin{array}{l}\text { Aumento de procura de } \\
\text { mão-de-obra }\end{array}$ & 0 & 0 & 0 & 0 & 0 & 0 & 0 & 0 \\
\hline $\begin{array}{l}\text { Aumento de vagas na } \\
\text { instituição de ensino }\end{array}$ & 0 & 0 & 0 & 0 & 0 & 0 & 0 & 0 \\
\hline Consumo de bens e serviços & 0 & 0 & 0 & -1 & 0 & 0 & 0 & 0 \\
\hline Geração de emprego & 0 & 0 & 0 & 0 & 0 & 0 & 0 & 0 \\
\hline $\begin{array}{c}\text { Aumento na procura por } \\
\text { empregos }\end{array}$ & 0 & 0 & 0 & 0 & 0 & 0 & 0 & 0 \\
\hline Total & -12 & -21 & -30 & -17 & -25 & -26 & -30 & -25 \\
\hline
\end{tabular}




\section{REA - Revista de estudos ambientais (Online) \\ v.20, n. 2, p.6-20, jul./dez. 2018}

Tabela 5 - Matriz de impactos fase de operação (Conclusão)

\begin{tabular}{|c|c|c|c|c|c|c|c|}
\hline \multicolumn{5}{|c|}{ MEIO SOCIOECONÔMICO } & \multicolumn{3}{|c|}{ MEIO BIÓTICO } \\
\hline MATRIZ & 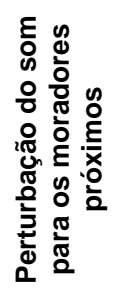 & 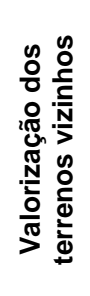 & 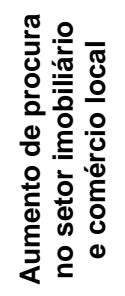 & 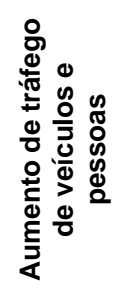 & 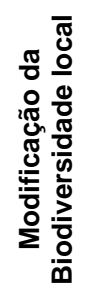 & $\begin{array}{l}\frac{0}{0} \\
\frac{\pi}{0} \\
\frac{0}{\pi} \\
\frac{\pi}{2} \\
\frac{0}{5} \\
\frac{\pi}{0} \\
\frac{\pi}{0} \\
\frac{\pi}{0} \\
\frac{\pi}{0} \\
\frac{0}{0}\end{array}$ & 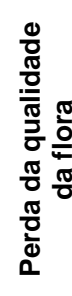 \\
\hline Impermeabilidade do solo & 0 & 1 & 0 & -5 & -5 & -5 & -5 \\
\hline Terraplanagem & 0 & 0 & 0 & 0 & 0 & 0 & 0 \\
\hline $\begin{array}{c}\text { Disposição inadequada de resíduos } \\
\text { sólidos }\end{array}$ & -1 & -1 & -1 & -5 & -10 & -10 & -10 \\
\hline $\begin{array}{l}\text { Aumento do fluxo de transportes } \\
\text { pesados }\end{array}$ & -5 & 1 & 1 & -5 & -5 & -5 & -5 \\
\hline Remoção da vegetação & 0 & -5 & -1 & -1 & -10 & -10 & -10 \\
\hline $\begin{array}{l}\text { Aumento do nível de barulho } \\
\text { provocado pelo fluxo de veículos }\end{array}$ & -5 & -1 & -1 & -1 & -1 & -1 & -1 \\
\hline Arrecadação de Impostos & 0 & 10 & 10 & 5 & 0 & 0 & 0 \\
\hline $\begin{array}{l}\text { Aumento de procura de } \\
\text { mão-de-obra }\end{array}$ & 0 & 1 & 10 & 5 & 0 & 0 & 0 \\
\hline $\begin{array}{l}\text { Aumento de vagas na } \\
\text { instituição de ensino }\end{array}$ & 0 & 5 & 10 & 0 & 0 & 0 & 0 \\
\hline Consumo de bens e serviços & 0 & 10 & 10 & 10 & 0 & 0 & 0 \\
\hline Geração de emprego & 0 & 10 & 10 & 10 & 0 & 0 & 0 \\
\hline $\begin{array}{c}\text { Aumento na procura por } \\
\text { empregos }\end{array}$ & 0 & 10 & 10 & 10 & 0 & 0 & 0 \\
\hline Total & -11 & 41 & 58 & 23 & -31 & -31 & -31 \\
\hline
\end{tabular}

Fonte: Adaptado de Sánchez (2013)

Com a verificação destas, obteve-se como resultado as Tabelas 6 e 7 . Estas mostram de forma mais objetiva os impactos e proporção dos mesmos sobre os meios em questão.

De acordo com o observado na Tabela 6 em conjunto com as considerações e aplicações da Tabela 3, na fase de implantação do empreendimento, o meio que será mais afetado sendo observado o somatório modular em $100 \%$ e vendo sua porcentagem com o resultado dado ao meio, totalizando $72,12 \%$ é o meio físico, seguido do meio biótico com $21,81 \%$ e por último o meio socioeconômico com 14,54\%. Percebe-se, nesta fase, que a quantidade de impactos negativos foi significativamente alta, com predominância entre relevante e severo (Tabela 3). No entanto, alguns impactos positivos também surgiram, tanto com predominância baixa, como média e alta.
Já na fase de operação (Tabela 7), verifica-se que o meio socioeconômico será o mais afetado, totalizando $43,54 \%$ de impactos, negativos e principalmente positivos, seguido do meio físico com $37,70 \%$ e biótico com $18,75 \%$, diferenciando-se da fase de implantação onde o meio físico foi o mais afetado.

Para a operação do empreendimento a maioria dos impactos obtidos, refere-se a negativos relevantes, isto é, com médio grau de impacto negativo. Em relação aos impactos positivos, estes apresentaram-se alto, e devem ser considerados como significantes para a implantação do empreendimento. De modo geral, (Tabelas 6 e 7), pode-se verificar alta perturbação do sistema de ampliação ao meio, no entanto a expansão da área é de extrema importância por ser fonte de ensino e pesquisa. 
REA - Revista de estudos ambientais (Online)

v.20, n. 2, p.6-20, jul./dez. 2018

Tabela 6 - Classificação dos impactos na fase de implantação

\begin{tabular}{|c|c|c|c|}
\hline & MATRIZ & Total & $\%$ \\
\hline \multirow{9}{*}{$\begin{array}{l}\text { Meio Físico = -238 } \\
(72,12 \%)\end{array}$} & Alteração da qualidade do solo & -45 & 18,91 \\
\hline & Erosão pluvial & -35 & 14,71 \\
\hline & Modificação da qualidade das águas & -31 & 13,03 \\
\hline & Geração de resíduos construção & -13 & 5,46 \\
\hline & Compactação e desestruturação do & & \\
\hline & solo & -26 & 10,92 \\
\hline & Assoreamento de rios & -26 & 10,92 \\
\hline & Alteração da qualidade do ar & -17 & 7,14 \\
\hline & $\begin{array}{c}\text { Alteração da paisagem e modificação } \\
\text { da permeabilidade }\end{array}$ & -45 & 18,91 \\
\hline \multirow{4}{*}{$\begin{array}{l}\text { Socioeconômico = } 48 \\
(14,54 \%)\end{array}$} & $\begin{array}{l}\text { Perturbação do som para os } \\
\text { moradores próximos }\end{array}$ & -7 & 11,48 \\
\hline & Valorização de terrenos vizinhos & 21 & 34,43 \\
\hline & $\begin{array}{l}\text { Aumento de procura no setor } \\
\text { imobiliário e comércio local } \\
\text { Aumento de trafego de veículos e }\end{array}$ & 34 & 55,74 \\
\hline & pessoas & -1 & 1,64 \\
\hline \multirow{3}{*}{ Biótico = -72 (21,81\%) } & Modificação da biodiversidade local & -28 & 38,89 \\
\hline & Perda da qualidade da fauna & -22 & 30,56 \\
\hline & Perda da qualidade da flora & -22 & 30,56 \\
\hline
\end{tabular}

Fonte: Adaptado de Sánchez (2013)

Tabela 7 - Classificação dos impactos na fase de operação

\begin{tabular}{|c|c|c|c|}
\hline & MATRIZ & Total & $\%$ \\
\hline \multirow{8}{*}{$\begin{array}{c}\text { Meio Físico = }-187 \\
(37,70 \%)\end{array}$} & Alteração da qualidade do solo & -12 & 6,42 \\
\hline & Erosão pluvial & -21 & 11,23 \\
\hline & Modificação da qualidade das águas & -30 & 16,04 \\
\hline & Geração de resíduos construção & -18 & 9,63 \\
\hline & Compactação e desestruturação do solo & -25 & 13,37 \\
\hline & Assoreamento de rios & -26 & 13,90 \\
\hline & Alteração da qualidade do ar & -30 & 16,04 \\
\hline & Alteração da paisagem e modificação da permeabilidade & -25 & 13,37 \\
\hline \multirow{4}{*}{$\begin{array}{c}\text { Socioeconômico }=216 \\
(43,54 \%)\end{array}$} & Perturbação do som para os moradores próximos & -11 & 5,09 \\
\hline & Valorização de terrenos vizinhos & 76 & 35,19 \\
\hline & Aumento de procura no setor imobiliário e comércio local & 98 & 45,37 \\
\hline & Aumento de trafego de veículos e pessoas & 53 & 24,54 \\
\hline \multirow{3}{*}{ Biótico = -93 (18,75\%) } & Modificação da biodiversidade local & -31 & 33,33 \\
\hline & Perda da qualidade da fauna & -31 & 33,33 \\
\hline & Perda da qualidade da flora & -31 & 33,33 \\
\hline
\end{tabular}

Fonte: Adaptado de Sánchez (2013)

\subsection{Plano de gestão}

Diante dos impactos levantados, elaborou-se um plano de gestão com medidas mitigadoras (M) e compensatórias (C) associadas a fase de implantação e operação das obras, o qual compreende ações que tendem a minimizar a ocorrência de impactos 


\section{REA - Revista de estudos ambientais (Online) v.20, n. 2, p.6-20, jul./dez. 2018}

ambientais negativos e contrabalançar impactos ambientais expressivos e irreversíveis, impactos estes que não podem ser minimizados.

Para o meio físico, o monitoramento da qualidade do solo poderá se dar através de análises químicas e físicas, com base na Associação Brasileira de Normas Técnicas (ABNT), citadas a seguir:

- NBR 6457 - Amostras de Solos Preparação para Ensaios de Compactação e Caracterização, Teor de Umidade Natural (ABNT, 1986);

(ABNT, 1984).

- NBR 7181 - Análise Granulométrica

Os dados podem ser coletados em cinco pontos diferentes, semestralmente, durante dois anos por pessoal capacitado, assim como, a qualidade da água deverá ser monitorada por mesmo período na região de influência direta do empreendimento próximo do rio Pardo, sendo as amostras coletadas, analisadas e comparadas com a resolução 357 Conama (BRASIL, 2005) e com a portaria no 2914 do Ministério da Saúde (BRASIL, 2011).

O monitoramento da qualidade do ar seria efetuado por pessoal técnico capacitado e multidisciplinar, para efetuar análises através de aparelho portáteis que verificam a qualidade do ar instantaneamente. Os parâmetros analisados e monitorados devem seguir da Resolução Conama 003 (BRASIL, 1990).

Para o meio biótico, deve-se ter um monitoramento dos impactos na flora, monitorando-se as áreas de mata, capoeiras, áreas agricultáveis que integram espécies de árvores nativas e exóticas, bem como um acompanhamento do crescimento das espécies presentes na região e das inseridas com fim de compensação pelos danos causados na remoção de espécies existentes para a implantação do empreendimento.

No meio social, será realizado o monitoramento dos impactos socioeconômicos, sendo utilizadas informações obtidas por estudos do IBGE e da Prefeitura Municipal de Frederico Westphalen, com visitas a população que reside no local para saber a real situação em que se encontra cada família. $O$ monitoramento irá envolver as regiões de influências indiretas $e$ as regiões de influências diretas do empreendimento, onde serão analisadas a forma de ocupação existente e a forma de uso do espaço territorial.

A fim de minimizar impactos em todos os meios, devem-se seguir propostas mínimas como minimizar a supressão da vegetação e realizar o plantio de mudas nas áreas afetadas, designar corretamente os resíduos sólidos gerados na obra e executar monitoramento ambiental, realizar aspersão de água nas vias de acesso interno durante as obras, isolar com cortina vegetal e instalar redutores de velocidade para controlar impactos sonoros. Todo o programa de monitoramento deve ser efetivado semestralmente, nos dois primeiros anos, com a finalidade de estimar os mais diferentes efeitos e impactos causados pela implantação do empreendimento nos meios social, físico, biológico e social.

Além disso, todas as medidas mitigadoras e compensatórias deverão ser implementadas por meio de um conjunto articulado de programas ambientais estabelecidos. O Programa de Comunicação Social do empreendimento deverá assegurar a disponibilização de informações e a participação da comunidade local afim de permitir o acompanhamento dos programas ambientais com transparência para garantir uma efetiva integração entre a comunidade acadêmica e a empresa que realizará a ampliação.

\section{Conclusão}

De acordo com o EIA o meio físico é o principal atingido de forma negativa quantos aos impactos da implantação e operação. Pelo exposto e com base nos resultados no âmbito do EIA, conclui-se pela viabilidade ambiental do empreendimento em suas diferentes fases por se tratar de desenvolvimento de educação e pesquisa, desde que aplicadas as medidas de controle, mitigação, compensação e monitoramento ambiental definidas no estudo.

Contudo medidas mitigatórias para minimizar os impactos negativos devem ser tomadas, assim fazendo com que após a finalização da obra existam mais impactos benéficos do que maléficos. Sendo que destas atividades a destinação adequada de resíduos e a reposição da vegetação tem destaque quanto a importância visual e biótica. 


\title{
REA - Revista de estudos ambientais (Online) v.20, n. 2, p.6-20, jul./dez. 2018
}

\author{
5 Environmental Impact Assessment (EIA) Applied to Expansion of Federal University of \\ Santa Maria - Campus Frederico Westphalen/RS
}

\begin{abstract}
Nowadays the issues related to the natural environment have worried society, taking universal proportions, for this reason, technical standard and laws are becoming increasingly important and effective. Therefore, licensing and environmental impact studies are being used as a tool, with the objective of minimizing socio-environmental impacts. This work had the aim to predicting all the impacts that could be caused during a possible expansion of the Federal University of Santa Maria (UFSM) Campus Frederico Westphalen/RS. The study included visits, bibliographical researches and analysis of documents and materials of the institution. Thereby, Leopold's matrix was used to "quantify" the activities degrees of impact, evaluating three possible forms of territorial expansion of the campus. It has been found that the second alternative respects the territorial limits and exploits in a less negative way the natural resources, having a positive balance when the negative points are observed. It was possible to observe that the EIA analyzed and raised the most important positive and negative impacts resulting from this expansion, aiming at the construction of infrastructure works and indicating the necessary measures to mitigate the main negative impacts.
\end{abstract}

Keywords: University expansion; Socio-environmental impact; Environmental exploration.

\section{Referências}

ASSOCIAÇÃO BRASILEIRA DE NORMAS TÉCNICAS - ABNT. NBR 6457/86: amostra de solo - preparação para ensaios de compactação e ensaios de caracterização. Rio de Janeiro, 1986.

\section{ASSOCIAÇÃO BRASILEIRA DE NORMAS TÉCNICAS - ABNT. Solo: Análise Granulométrica NBR 7181-84, 1984.}

BRASIL. Constituição Federal do Brasil. Estabelece os princípios da Política Nacional do Meio Ambiente, 1988.

BRASIL. Lei $n^{\circ} 6.938$ de 1981. Dispõe sobre a Política Nacional do meio Ambiente. Diário Oficial da União, 1981.

BRASIL. Resolução CONAMA n`237, de 19 de dezembro de 1997. Dispõe sobre a revisão e complementação dos procedimentos e critérios utilizados para o licenciamento ambiental. Brasileira. Diário Oficial, 1997.

BRASIL. Resolução CONAMA ํㅜ 001, de 23 janeiro de 1986. Dispõe sobre as diretrizes gerais para uso e implementação de Avaliação de Impacto Ambiental. Brasileira. Diário Oficial, 1986.

BRASIL. Resolução CONAMA no 357 de 2005. Dispõe sobre a classificação dos corpos de água e diretrizes ambientais para o seu enquadramento, bem como estabelece as condições e padrões de lançamento de efluentes, e dá outras providências, 2005.

BRASIL. Resolução CONAMA no. 003, de 28 de junho de 1990. Dispõe sobre padrões de qualidade do ar, previstos no PRONAR. Diário Oficial da União, 1990.

BRASIL. MINISTÉRIO DA SAÚDE. Portaria MS no 2914, de 12/12/2011.: Dispõe sobre os procedimentos de controle e de vigilância da qualidade da água para consumo humano e seu padrão de potabilidade. 2011.

EMBRAPA- Ministério da Agricultura, Pecuária e Abastecimento. Estudos de Solos do Município de Frederico Westphalen, RS. 2011. Disponível em: $<$ http://ainfo.cnptia.embrapa.br/digital/bitstrea m/item/45561/1/CIRCULAR-TECNICA-

116.pdf>. Acesso em: 11 nov. 2015.

FINUCCI, M. Metodologias utilizadas na avaliação do impacto ambiental para a liberação comercial do plantio de transgênicos. 2010. 230f. Dissertação (Programa de Pós-graduação em Saúde Pública) - Faculdade de Saúde Pública da Universidade de São Paulo. São Paulo-SP.

IBGE. Censo demográfico de Frederico Westphalen-RS. Instituto Brasileiro de Geografia e Estatística-IBGE, 2010.

IBGE. Mapa de Biomas: O Mapa de Vegetação do Brasil. Instituto Brasileiro de Geografia e Estatística-IBGE, 2004. 


\section{REA - Revista de estudos ambientais (Online)}

v.20, n. 2, p.6-20, jul./dez. 2018

MAFFRA, C. R. B. Fitossociologia de um fragmento de Floresta Estacional Decidual na Região do Alto Uruguai - RS. Frederico Westphalen: UFSM, 2011. 46f. Trabalho de Conclusão de Curso (Graduação em Engenharia Florestal) - Centro de Educação Superior Norte do RS, Universidade Federal de Santa Maria, 2011.

OLIVEIRA, A. A. de; BURSZTYN, M. Avaliação de impacto ambiental de políticas públicas. Interações - Revista Internacional de Desenvolvimento Local, Campo Grande, v. 3, n. 3, p.45-56, set. 2001.

OLIVEIRA, F.C.; MOURA, H.J.T. de. Uso das metodologias de avaliação de impacto ambiental em estudos realizados no Ceará. PRETEXTO, v.10, n.4, p.79-98. 2009.

ORTIGARA, C. et al. Uso do solo e propriedades físico-mecânicas de Latossolo Vermelho. Revista Brasileira de Ciência do Solo, v.38, n.2, p.619-626. 2014.
PEREIRA, V. D.; GÓES, V. C. Análise do EIA/RIMA do Terminal de Combustíveis da Paraíba (TECOP) para fins de licenciamento ambiental. Principia, João Pessoa, v. 30, n. 439, p.39-47, set. 2016.

PREFEITURA MUNICIPAL DE FREDERICO WESTPHALEN / RS. Plano municipal de saneamento básico de Frederico Westphalen / RS: Diagnóstico da Situação. 2011.

SÁNCHEZ, L. E. Avaliação de impacto ambiental: conceitos e métodos. 583 p. ed. São Paulo: Oficina de Textos, 2013.

SKRZEK, D. P. M. \& POSSAN, E. Avaliação do aspecto da dimensão ambiental na adoção de práticas sustentáveis na construção civil em Cascavel, PR. Revista de Estudos Ambientais, v. 14, n. 2, p. 14-27, 2012. 